\title{
Distribution of azithromycin for the treatment of trachoma
}

Trachoma remains the world's leading infectious cause of blindness and the leading cause of ocular morbidity. Despite this, there is increasing hope of eradicating trachoma as a blinding disease and ending the years of suffering caused by trachoma. Much of the world is now free from trachoma because of improved standards of housing and hygiene. In poorer regions, however, trachoma remains hyperendemic. These areas include parts of Africa, Asia, the Middle East, and also Aboriginal communities in Australia. The World Health Organisation (WHO) estimates that 146 million people worldwide are presently infected by trachoma. ${ }^{1}$ Over ten million adults suffer from trichiasis that without corrective surgery will render them unnecessarily blind. An additional six million others are presently blinded by trachomatous corneal scarring. The development of an integrated attack on trachoma by the WHO aims to prevent the development of further trachomatous blindness. ${ }^{2}$

Total eradication of the causative organism of trachoma, Chlamydia trachomatis, does not seem to be a necessarily achievable and desirable goal. Moreover, it would not prevent the progression to blindness of those people previously infected. Both in terms of feasibility and effectiveness, the eradication of trachomatous blindness is a more realistic and preferable goal. The "SAFE strategy" developed by the WHO uses a combination of activities including Surgery for trichiasis, Antibiotic treatment of active chlamydial infection, the promotion of Facial cleanliness, and improvement of Environmental conditions. ${ }^{2}$

The antibiotic component of the SAFE strategy has been revolutionised by the introduction of azithromycin..$^{3-7}$ It is used as a single oral dose- $20 \mathrm{mg} / \mathrm{kg}$ for children and $1 \mathrm{~g}$ for adults.

As an effective and safe single dose oral preparation, azithromycin is far superior to the messy ointments that had to be used twice a day for weeks on end. Azithromycin has fewer side effects than many previously used antibiotics such as tetracycline, sulphonamides, or rifampicin. ${ }^{8}$ Because of its broad spectrum, especially for Gram positive organisms, azithromycin offers the additional advantage of concurrently treating most respiratory, skin, and genital infections. The systemic administration leads to the treatment of any chlamydial infection of the other mucosal surfaces and this prevents chlamydial reinfection from autoinoculation. The ease of use as a single, oral dose, its safety, and its efficacy for ocular and extraocular infection all contribute to the high rates of compliance and community acceptance seen with azithromycin. In practice, this means that azithromycin is likely to be as effective in actual use as it was in clinical trials.

However, the effective and cost effective treatment of communities with azithromycin depends on the principles of targeting the infectious pool and using community based distribution. Active infection with trachoma clusters within childcare groups, hence its characterisation as "a disease of the crèche". The infectious pool includes children, especially preschool children, mothers, and women involved in child care. Within this group, tears and secretions infected with chlamydia are frequently and easily swapped among the young children and their caretakers leading to repeated episodes of reinfection. ${ }^{9-11}$ Girls are likely to have active trachoma longer than boys, and women may be up to three times more frequently blinded by trachoma. ${ }^{12}$

At high prevalence rates, most families in endemic communities will have at least some children with active trachoma. However, as the prevalence falls, infection becomes more noticeably clustered so that usually only a few families will have most of their children affected, whereas in most other families no one will have active trachoma.

Given the clustering of active trachoma and its family based transmission, treatment should be targeted to treat the "transmission units" or those families in which there are infected children. This targeting is important to reduce both the cost and the potential of unnecessary adverse reactions from treating those who do not need to be treated. Targeting also optimises the impact of treatment by revealing all those who need to be treated and allowing complete treatment coverage.

For family based treatment to occur, one needs to identify in the community those families that have children with active trachoma. Families without active transmission do not need, and will not benefit from, treatment. For this purpose a family may be considered as those people who live together or share a sleeping area.

Children should be screened for trachoma by examining the everted upper eyelid with magnification of two times or greater, and by using the WHO simplified trachoma system. ${ }^{13}$ Typically, active trachoma-that is, follicular and inflammatory trachoma, will be concentrated in children, scarring trachoma in adults, trichiasis and corneal opacity in the middle aged and more elderly.

Once one child in a family is clinically identified with trachoma, the other children in that family do not require individual examination as all members of the family require empirical treatment. Conversely, a family cannot be excluded from treatment until every child in the family has been examined and found to be disease free.

For screening purposes, schoolchildren often provide a convenient group; however, preschool aged children form a more epidemiologically sensitive and representative group to screen. One screening strategy is to examine schoolchildren for the initial identification of families with active trachoma, and to follow this by further screening of families that have either only preschool aged children or children not in school, or to examine the preschool children of families with school aged children who did not have active trachoma on initial screening. Families without children may be automatically excluded from those needing treatment, although adults with trichiasis need identification and surgical treatment.

The key to any treatment strategy is community involvement in distribution. For example, this has proved to be both the most effective and the most cost effective method of distributing ivermectin. ${ }^{14}$ Community health workers are valuable assets to a treatment programme. Treatment should focus on the women and children-that is, the members of the crèche, but treatment should also be offered to all members of the affected families, including men. The community based treatment of affected families of a community is best if done at the same time to promote 
good coverage. With reasonable coverage, catch up treatment rounds are probably not warranted. Retreatment should be offered to families at a one year interval if family members show signs of reinfection and active disease on re-examination.

Azithromycin is but one of the four critical components contained in the WHO SAFE strategy for the prevention of trachomatous blindness. It is important not to forget the others-namely trichiasis surgery, facial cleanliness, and the improvement of environmental conditions for hygiene and sanitation. To eliminate trachoma and blindness from trachoma, each of the SAFE strategy components must be successfully implemented.

Trachoma remains a disease indicative of disenfranchisement and social marginalisation. It disproportionately affects the most disadvantaged members within communities, the poorest and dirtiest, those who have the least access to water, sanitation, and housing. But the solution to trachoma is more complicated than "just add water". Beyond water provision are the facets of infrastructure and social development that eliminated trachoma from many parts of the world decades before the advent of antibiotics. Although an important and exciting advance, azithromycin on its own, is not a magic bullet. Much hard work remains to be done.

KATHRYN I TAYLOR HUGH R TAYLOR

Centre for Eye Research Australia, University of Melbourne, Melbourne, Australia
1 World Health Organisation. Future approaches to trachoma control. Report of a global scientific meeting. Geneva: WHO/PBL96.56, 1996.

2 Francis V, Turner V. Achieving community support for trachoma control. A guide for district health work. World Health Organisation, Edna McConnell Clark Foundation. Geneva: WHO/PBL93.36, 1996.

3 Bailey RL, Arullendran P, Whittle HC, et al. Randomised controlled trial of single-dose azithromycin in treatment of trachoma. Lancet 1992;231:4536.

4 Dawson CR, Schachter J, Sallam S, et al. A comparison of oral azithromycin with topical oxytetracycline/polymyxin for the treatment of trachoma in with topical oxytetracycline/polymyxin

5 Tabbara KF, El-Asrar AM, Al-Omar O, et al. Single-dose azithromycin in the treatment of trachoma. A randomized, controlled study. Ophthalmology 1996;103:842-6.

6 Schachter J, West S, Mabey D, et al. Azithromycin in control of trachoma. 3. Effect of treatment on Chlamydia trachomatis infection in trachoma. In: Stephens RS, Byrne GI, Christiansen G, et al, eds. Chlamydial infection. Proc Ninth International Symposium on Human Chlamydial Infection. San Francisco, CA, 1998:347-50.

7 Mabey D, Bailey R, Faal H, et al and the ACT Group. Azithromycin in control of trachoma. 2. Community based treatment of trachoma with oral azithromycin: a one year follow-up study in The Gambia. In: Stephens RS, Byrne GI, Christiansen G, et al, eds. Chlamydial infection. Proc Ninth InterByrne GI, Christiansen G, et al, eds. Chlamydial infection. Proc Ninth International Symp

8 Hoepelman IM, Schneider MME. Azithromycin: the first of the tissueselective azalides. Int $\mathcal{f}$ Antimicrobiol Agents 1995;5:145-67.

9 Taylor HR, Johnson SL, Prendergast RA, S et al. An animal model of trachoma. II. The importance of repeated reinfection. Invest Ophthalmol Vis Sci 1982;23:507-15.

10 Taylor HR, Rapoza PA, Johnson S, et al. The epidemiology of infection in trachoma. Invest Ophthalmol Vis Sci 1989;30:1823-33.

11 West SK, Rapoza P, Muñoz B, et al. Epidemiology of ocular chlamydial infection in a trachoma-hyperdendemic area. F Infect Dis 1991;163:752-6.

12 Turner VM, West SK, Muñoz B t al Risk factors for trichiasis in women. A case-control study. Int $\mathcal{F}$ Epidemiol 1993;22:341-7.

13 WHO Programme for the Prevention of Blindness. Primary health care level management of trachoma. Edna McConnell Clark Foundation. Geneva: management of trachoma. Edna McConnell Clark Fou
World Health Organisation, WHO/PBL/93.33, 1993.

14 World Health Organisation. Onchocerciasis and its control. Report of a WHO expert committee on onchocerciasis control. Geneva: WHO Technical Book Series, 852, 1995.

\section{Contributors please note:}

Communications from the UK, Republic of Ireland, Australasia, Asia, Africa, Japan, and the Middle East should be sent to the Editor, British Journal of Ophthalmology, Department of Ophthalmology, University of Aberdeen, Medical School, Foresterhill, Aberdeen AB25 2ZD, Scotland, UK (Tel: 01224 663812; Fax: 01224 663832).

Communications from Western Europe, Eastern Europe, the former Soviet Union, and Scandinavia should be sent to Professor A Kijlstra, Associate editor, The Netherlands Ophthalmic Research Institute, PO Box 12141, Meibergdreef 9 , 1100 AC Amsterdam, Netherlands (Tel: +31 20 5664535; Fax: +31 20 6913401).

Communications from the USA, Canada, and South America should be sent to Professor C Hoyt, Associate editor, University of California, UCSF Ophthalmology Department, Pediatric Ophthalmology, 400 Parnassus Avenue, Room 702 A, Box 0344, San Francisco, CA 94143, USA (Tel: +415 476 1289/1921; Fax: +415 502 6468). 